Paper ID \#19814

\title{
Entrepreneurial Thinking in a First-Year Engineering Design Studio
}

\section{Dr. Ashley Bernal, Rose-Hulman Institute of Technology}

Ashley Bernal is an Assistant Professor of Mechanical Engineering at Rose-Hulman Institute of Technology. She received her PhD from Georgia Institute of Technology in 2011. She was an American Society of Mechanical Engineers (ASME) teaching fellow and Student Teaching Enhancement Partnership (STEP) Fellow. Prior to receiving her PhD, she worked as a subsystems engineer at Boeing on the Joint Unmanned Combat Air Systems (JUCAS) program. Her research areas of interest include piezoelectrics, nanomanufacturing, optical measuring techniques, and intercultural design.

\section{Dr. Patricia Brackin P.E., Rose-Hulman Institute of Technology}

Patricia Brackin is a Professor of Mechanical Engineering at Rose-Hulman Institute of Technology, where she teaches design throughout the curriculum. She is particularly interested in sustainable design. Her B.S. and M.S. are from the University of Tennessee in Nuclear Engineering and her Ph.D. is from Georgia Institute of Technology in Mechanical Engineering. Her industrial experience includes Oak Ridge National Laboratories, Chicago Bridge and Iron, and a sabbatical at Eli Lilly. She is a registered Professional Engineer in the State of Tennessee.

\section{Dr. Richard A. House, Rose-Hulman Institute of Technology}

Richard A. House is Professor of English at Rose-Hulman Institute of Technology. He received a B.A. from Illinois Wesleyan University and M.A. and Ph.D. from the University of California, Irvine. His interests include liberal education for engineers, engineering communication and pedagogy, sustainability, and Shakespeare. He is co-author (with Richard Layton, Jessica Livingston, and Sean Moseley) of The Engineering Communication Manual, published by Oxford University Press.

\section{Prof. Jay Patrick McCormack, Rose-Hulman Institute of Technology}

Jay McCormack is an associate professor in the mechanical engineering department at Rose-Hulman Institute of Technology. Dr. McCormack received his $\mathrm{PhD}$ in mechanical engineering from Carnegie Mellon University in 2003. His areas of research interest include engineering education, computational design, and manufacturing.

\section{Dr. Anneliese Watt, Rose-Hulman Institute of Technology}

Anneliese Watt is a professor of English at Rose-Hulman Institute of Technology. She teaches and researches technical and professional communication, rhetoric and composition, medicine in literature, presidential election rhetoric and other humanistic studies for engineering and science students. Her current work focuses on engineering design.

\section{Mr. Bill Riley, Saint Mary-of-the-Woods College}

Bill Riley is Assistant Professor of English at Saint Mary-of-the-Woods College near Terre Haute, Indiana, where he directs the Professional Writing major. 


\section{Entrepreneurial Thinking in a First-Year Engineering Design Studio}

In summer 2016, the authors and several other collaborators developed and taught a course aiming to advance the pedagogy informing a proposed new degree program in Engineering Design, in which design, writing, and engineering topics are integrated into a multidisciplinary design studio setting. Most closely associated with the disciplines of industrial design and architecture, design studios immerse students in an authentic problem-solving environment:

"In studio, designers express and explore ideas, generate and evaluate alternatives, and ultimately make decisions and take action. They make external representations (drawings and three-dimensional models) and reason with these representations to inquire, analyze, and test hypotheses about the designs they represent. Through the linked acts of drawing, looking, and inferring, designers propose alternatives, and interpret and explore their consequences. ... They use the representations to test their designs against a priori performance criteria. And in the highly social environment of the design studio students learn to communicate, to critique, and to respond to criticism, and to collaborate." 1

Studio experiences are much rarer in engineering education. As a result, varying specializations, activities, and skills within the engineering profession are divided into numerous special purpose courses, and students are not always fully supported in the necessary process of integrative learning. In particular, the general domains of design and analysis are separated more often than they are blended. (Moreover, communicating the results of these activities is often relegated to a secondary status rather than an intrinsic part of engineering thinking.)

\section{The History of Studio Education and Its Application to a Design Curriculum}

In architecture education, the studio format was inherited from the atelier, the default setting for arts education from the Middle Ages onward, in which apprentices learned their craft in the studio of the master. (Completing this training led to the status of a journeyman artist; some journeymen might then become masters themselves.) In the Ecole des Beaux-Arts of the late 19 th century, the studio was formalized as an academic system, with today's arts and design education preserving it essentially intact.

For painters or architects, the studio represents intense specialization, its curriculum consisting of fundamental techniques of the student's intended profession. Nevertheless, studio education has always encompassed the technical, the practical, and the artistic in a unified experience with clear, consistent purpose that is much more difficult to achieve when component skills or disciplines are parsed into unconnected courses. In their taxonomy of higher education outcomes, the Association of American Colleges and Universities identifies a set of outcomes as belonging particularly to integrative learning. ${ }^{2}$ For the introductory studio course that we piloted in our summer 2016 version the learning outcomes were defined by the three constituent courses: Introduction to Design (a course in the engineering curriculum), Rhetoric and Composition, and Graphical Communication (which teaches solid modeling techniques). The learning outcomes 
for each of these individual courses - tracked with some care to ensure that all were achieved in the new studio experience - are shown in Table 1.

Table 1. Learning outcomes from the three individual source courses, maintained as stated learning outcomes for the integrated studio course.

\begin{tabular}{|c|c|c|}
\hline $\begin{array}{l}\text { Rhetoric and Composition } \\
\text { (RH131) }\end{array}$ & $\begin{array}{l}\text { Introduction to Design } \\
\text { (EM103) }\end{array}$ & $\begin{array}{c}\text { Graphical Communication } \\
\text { (EM104) }\end{array}$ \\
\hline $\begin{array}{l}\text { Effectively } \\
\text { communicate } \\
\text { the goals, } \\
\text { methods, and } \\
\text { outcomes of } \\
\text { design } \\
\text { objectives } \\
\text { Develop } \\
\text { familiarity } \\
\text { with rhetorical } \\
\text { situations } \\
\text { Attend to the } \\
\text { processes of } \\
\text { writing } \\
\text { Develop } \\
\text { research and } \\
\text { documentation } \\
\text { skills } \\
\text { Practice } \\
\text { critical } \\
\text { thinking } \\
\text { Practice basic } \\
\text { grammatical, } \\
\text { stylistic, and } \\
\text { mechanical } \\
\text { rules and } \\
\text { patterns }\end{array}$ & $\begin{array}{l}\text { Determine the } \\
\text { needs of a } \\
\text { stakeholder } \\
\text { and describe } \\
\text { the technical, } \\
\text { social, } \\
\text { environmental, } \\
\text { and economic } \\
\text { context of the } \\
\text { problem } \\
\text { Develop } \\
\text { alternative } \\
\text { design } \\
\text { concepts and } \\
\text { evaluation } \\
\text { criteria } \\
\text { Use } \\
\text { mathematical } \\
\text { modeling and } \\
\text { prototyping to } \\
\text { refine a design } \\
\text { concept and } \\
\text { establish its } \\
\text { feasibility } \\
\text { Describe } \\
\text { behaviors that } \\
\text { contribute to } \\
\text { effective } \\
\text { teamwork } \\
\text { Identify the } \\
\text { relevance of } \\
\text { professional } \\
\text { ethics in } \\
\text { project work } \\
\text { Describe the } \\
\text { design process } \\
\text { as introduced } \\
\text { in this course }\end{array}$ & $\begin{array}{l}\text { Move between 2-D } \\
\text { and 3-D } \\
\text { representations of an } \\
\text { object. } \\
\text { - See the shapes that } \\
\text { make an object and to } \\
\text { use these shapes to } \\
\text { create a plan for } \\
\text { modeling the object. } \\
\text { Create model features } \\
\text { in a systematic manner } \\
\text { consistent with the } \\
\text { design intent of the } \\
\text { part } \\
\text { Create proper sketches } \\
\text { during part creation. } \\
\text { Create solid models } \\
\text { that accurately } \\
\text { represent the part and } \\
\text { design intent and are } \\
\text { easy for other people } \\
\text { to use, update, and } \\
\text { change } \\
\text { Create proper } \\
\text { assemblies } \\
\text { Create proper } \\
\text { engineering drawings } \\
\text { to communicate a } \\
\text { design } \\
\text { "Explode" an } \\
\text { assembly and to } \\
\text { animate the explosion } \\
\text { to show the intended } \\
\text { sequence of part } \\
\text { assembly. } \\
\text { - }\end{array}$ \\
\hline
\end{tabular}


We regarded it as crucial, however, to unify the tools and processes of these courses within a theme that defined shared problems and contexts for all of the students' design and writing work. The studio experience relied on such a theme to help avoid the risk of falling apart into a mere collection of separate assignments without a sufficiently compelling unifying conceit.

For our course, this conceit was provided by the field of disability studies. The experience of people with disabilities provided texts for rhetorical analysis, cultural issues for research and informed debate, and practical needs on which student designers could work to solve authentic problems experienced by real users. We were able to implement this intellectual framework as an authentic service learning experience by partnering with Reach Services (formerly United Cerebral Palsy), a nonprofit agency providing numerous services for local people with disabilities. One of Reach's offerings is a library of toys and games with adaptive accommodations making them accessible to children with various types of disabilities: the design of new toys for this library became the culminating design project for students.

\section{The KEEN Framework and the "3 C's"}

The course was designed from the start to develop the "3 C's" that define the entrepreneurial mindset within the KEEN framework-developing curiosity, making connections, and creating value - which, in our minds, constitute another formulation of integrative learning. However, the disability studies content created a particular urgency for each of these dimensions:

- $\quad$ Curiosity is required to identify the needs of users with disabilities. Students needed not only to acquire information about various types of disabilities (emotional, intellectual, fine and gross motor, etc.), but also to become curious about the life experiences of users in the various categories.

- Making connections was particularly important in exploring the relationships among the studio's constituent courses. Readings on theory within the field of disability studies might initially "belong" to the Rhetoric and Composition course and associated writing assignments, but become valuable input to student design projects.

- Creating value in this case applies most directly to individual users of students' completed projects, achieving social good. At the same time, economic considerations were always relevant: existing toys and games with accommodations for users with disabilities are quite expensive.

\section{Overview of the Curriculum and Assignments}

For the engineering design program, the course was driven by three major assignments. For the first assignment, "Reverse Rhetoric and Engineering," the students were tasked with analyzing a child's toy "The corn popper", shown in Figure 1, based on its rhetoric and engineering (i.e. students were supposed to make sophisticated arguments about how the design, packaging, and/or advertising persuades consumers about who the product is and isn't for). In addition, the students were to discuss how the product technically works including images of solid models (i.e. computer models) with labels that complement their arguments. Figure 1a shows an 
exploded view of a solid model created by one student that was used to explain the working of the toy. Figure $1 \mathrm{~b}$ shows an actual picture of the toy. While having the students work on the corn popper, we also used bottle openers, including ones that have been developed for use with a single hand, in order to provide an in-class example.

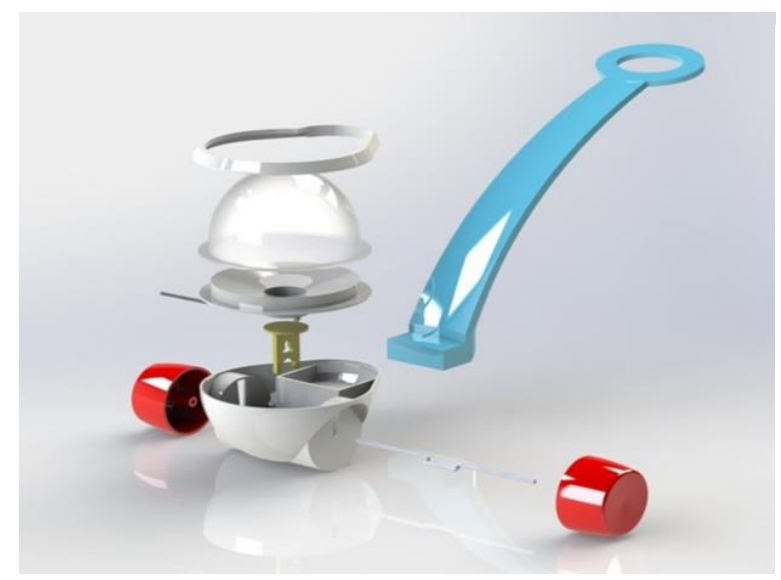

(a)

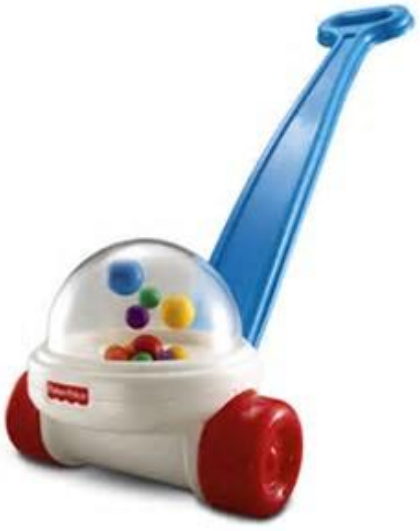

(b)

Figure 1. a) Solid Model constructed by student showing the exploded view of child's corn popper and b) picture of actual product.

The second assignment required students to investigate ongoing engineering work at our campus's startup/business incubator (Rose-Hulman Ventures), producing ethnographic insights by observing as comprehensively as possible actions, statements, and activities that occurred. They were to note how decisions were made, conclusions reached, and problems solved including what kinds of evidence, reasoning, and persuasion that were used to communicate to others. In addition, the students were to reflect on whether and how their observations fit their beliefs about what engineers do and how engineering works. The resulting written ethnography targeted an audience of high school juniors interested in engineering as a potential career, persuading these prospective engineering students of assertions or claims about engineering with evidence from onsite observations.

The final and most ambitious project assignment was to modify or develop a new toy for Reach Services' Lending Library. Reach Services is an organization that provides comprehensive services to individuals and families of all ages facing a wide spectrum of challenges and disabilities. In particular, the lending library provides toys for parents, teachers, and therapists to borrow to help meet children's needs.

After each major assignment, students were asked to reflect on what they had accomplished with regard to each of the KEEN "3C's." The only prompt was a display of the KEEN framework, shown in Figure 2, on the classroom screen. The major headings for Curiosity, Connections, and Creating Value were pointed out to students:

"Curiosity: In a world of accelerating change, today's solutions are often obsolete tomorrow. Since discoveries are made by the curious, we must empower our students to investigate a rapidly changing world with an insatiable curiosity." 
"Discoveries, however, are not enough. Information only yields insight when connected with other information. We must teach our students to habitually pursue knowledge and integrate it with their own discoveries to reveal innovative solutions."

"Innovative solutions are most meaningful when they create extraordinary value for others. Therefore, students must be champions of value creation. As educators, we must train students to persistently anticipate and meet the needs of a changing world."

Students were given approximately 30 minutes to write after each major deliverable was completed and at the very end of the course.

\section{MINDSET + SKILLSET EDUCATION IN TANDEM}

\section{ENTREPRENEURIAL MINDSET (The 3C's)}

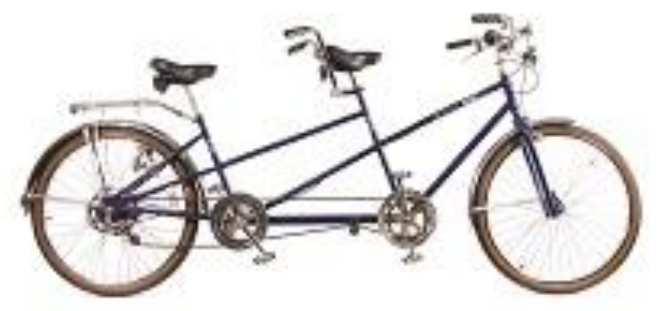

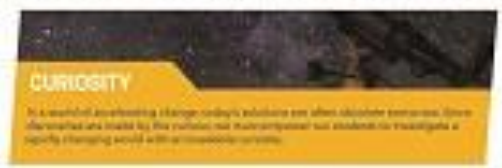

+ ENGINEERING SKILLSET

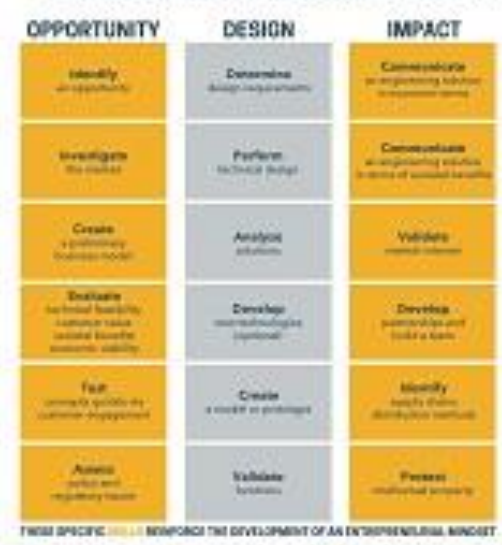

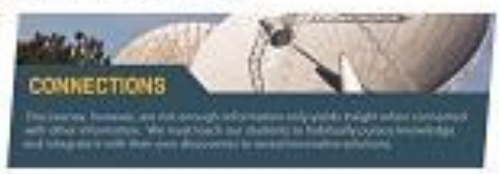

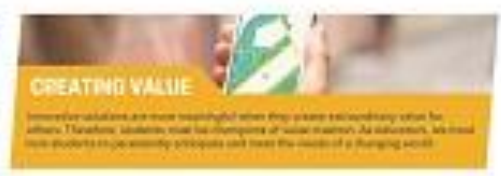

= EDUCATIONAL OUTCOMES

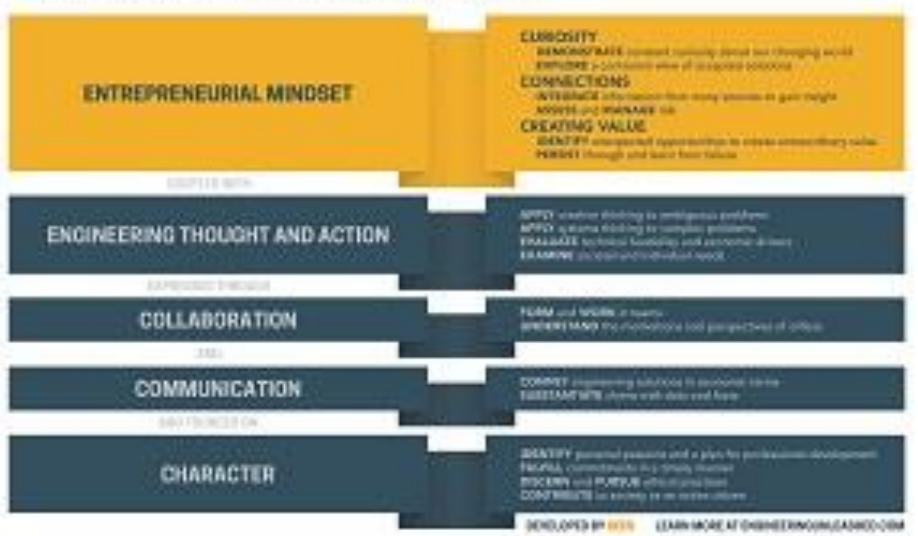

Figure 2. The KEEN Framework provided to the students when writing their reflections. ${ }^{3}$

Interestingly - though we had not planned this - students associated each major assignment with a primary "C". As students saw it, the reverse rhetoric assignment highlighted connections among various disciplinary methods and bodies of knowledge. The ethnography assignment elicited their curiosity about a possible future an engineer at a company. Through their product designs in the final project, they expressed pride in having created what they thought was extraordinary value for individuals with disabilities. 
As they completed the final reflective writing, we asked students to consider the entire program comprehensively. As students revisited the earlier assignments, their thinking about them in some cases became more sophisticated: "Along with that using SolidWorks got us thinking. In SolidWorks there is no one way of doing things. Every piece can be created using a wide variety of method, so that caused us to think about different creation methods such as a sweep, a cut extrude, or a revolve." Instead of just saying "SolidWorks is hard," this student now recognizes multiple, creative ways to solve every design problem, even at the level of creating particular parts. We perceive this as an unusually mature insight: for instance, it far exceeds the typically dualistic worldview predicted for entering first-year students in Perry's Scheme of Intellectual Development. $^{4}$

Even such advanced insights and metacognitive awareness, though, arose through fairly gradual development in student reflections prompted by questions about each of the " $3 \mathrm{C}$ 's" dimensions throughout the course.

\section{Student Reflections: Curiosity}

Throughout the course, most students reported curiosity on those tasks and questions that they identified most closely with their aim of entering the engineering profession. This reflects not only students' chosen career path, but the characteristic early-undergraduate perceptions of disciplines noted by Perry and by Rapaport: students see some disciplines — science and mathas offering accessible, agreed-upon truths. ${ }^{4,5}$ (Authentic curiosity in more textual and rhetorical disciplines must sometimes wait for students to enter stages of relativism and multiplicity in the Perry Scheme.) In our course, expressions of curiosity reflected a preference for and a preoccupation with engineering practice perceived as authentic, which they often equated with hands-on tinkering and building activities. (Some also reported that hands-on activities such as machining and wiring, satisfied or stimulated their desires for creative activity.)

On the "Reverse Rhetoric and Engineering" assignment: "Curiosity began with the disassembly part of the project. We discovered how each unit worked for itself by ripping it up and observing how each individual part came together to form a whole." One student's curiosity about a particular small injection-molded part received praise from several peers. The student leading this effort wrote about both his hands-on exploration and the conclusion to which it led:

While deconstructing the Fisher-Price corn popper there were a couple of pieces that peaked our curiosity. One piece that allowed us to think through why it was there was the yellow popper piece and the tips on top of the part. We all originally thought that the tips might have something to do with preventing the part from becoming jammed. I questioned that though and went into the shop and cut off the tips and put the parts back together to see if it still functioned. It still functioned and did not have jamming issues so we came to the conclusion that the company just kept that piece from the old model. I believe that Fisher-Price probably thought about the yellow piece and had the same question, and I also believe that they kept the tips to conserve money by not having to create a new injection mold. 
Two students did mention that the assignment prodded them to contemplate how toys designed for mass production markets exclude those with disabilities. One of those students also referred in her reflection to the activities in class that examined "one arm openers, the deaf video" and other materials that explicitly call attention to the problem of designing for the experience of disability. She also discussed exploring current products and their accompanying rhetoric.

Another student mentioned computer modeling, but not in terms of how the modeling intersected with her thoughts about the design of the product - as we might have hoped — but instead more reductively: "We all had many questions about Solidworks modelling, and we were able to learn the answers to these questions and improve our skills." The Perry Scheme places such questions in "early multiplicity," focusing on open questions but only with an eye toward resolving them with factually correct answers. ${ }^{4,5}$

Similarly to their hands-on work in the studio, students associated curiosity with physical travel - trips to visit a GE plant, including their rapid prototyping center, and GE FirstBuild, an innovation laboratory, and even the toy section of a superstore. Their ethnographic observation at our campus startup incubator gave them "the opportunity to demonstrate a constant curiosity about what it would be like to be an engineer." They wondered about what the environment would be like at an engineering firm and explored the relationship between engineers and technicians. On this assignment, students reported that curiosity "was the most abundant ' $\mathrm{C}$ ' because we are all rising engineers." The ethnographic observation was originally proposed by our team's rhetoric and writing experts to expose students to professional engineering discourse - a lens and intellectual framework that seemed to give way to students' own sense of engineering as applied science, appreciating the opportunity "to watch more experienced engineers perform experiments and actually implement the scientific process."

If curiosity early in the class related to the students" existing interests, the major "Design for Disability" project seemed to open that curiosity in additional directions. Some reflections continued to emphasize the acquisition of technical knowledge. ("It was great to learn about different adaptive technologies and their many applications"; "we were able to learn about what makes a remote control car work.") In general, though, students became more aware of human elements and interpersonal processes. Many students focused on the end user, aspiring to "help middle school children overcome disabilities and interact with the world around them." This emphasis on users seemed also to prompt attention to interpersonal interactions during the design process itself, especially in interactions with our client agency, Reach Services: "we asked what would work the best and did more investigation into remote controls and disability. A great deal of our project planning relied on asking questions about what would best benefit a user with a disability and how we could improve the ease of use of our device."

Other expressions of curiosity focused not on authentic professional development as a student engineer, but on the opportunity to authentically adopt the identity of a college student:

This course in hindsight, was one of the best decisions I made. I still remember the day I got my Rose-Hulman acceptance letter, and pretty much making up my mind that I would attend the school no matter what. When I got the initial email from Dr. Brackin about the Engineering Design course, I didn't think of it as a "oh man starting school early means 
cutting into summer", but instead "oh man, I'm going to get to experience real college in a smaller setting, and meet new people in the same boat as me". I was more curious than anything to start being a college kid.

Other students also commented that the very act of choosing to join an experimental program, never previously offered, demonstrated the curiosity they brought to their educational endeavors.

\section{Student Reflections: Connections}

On occasion, "Connections" became another occasion to reason about the applicability of course content to students' imagined future careers. This happened most often when students reflected on their ethnographic observation of the startup incubator as an engineering workplace. This perceived connection ranged from the hands-on ("gaining an insight to how to do some electrical work, such as soldering, will hopefully prove to be of use to me in the future") to the discursive (rhetorical appeals discussed in class appeared between "coworkers in everyday conversations and...between an employee and a supervisor"). Several students formulated this as a connection between classroom and workplace: for instance, they recognized undergraduate interns as "knowledgeable enough to work for a company," causing them to reflect on "what I have learned so far in the classroom and how it is used in jobs." Everything from shop tools to software showed up in this reasoning: they saw SolidWorks used to communicate ideas to clients as well as "seeing machines in the machine shop that we have already used" and "taking measurements with a caliper like we have been doing."

More often, though, students commented on the design of the course curriculum and assignments, "integrating information from three different classes into one condensed class." ("The very idea of this course is meant to encourage the connections between design, rhetoric, and engineering.") Sometimes, students seemed to paraphrase our own explicit and implicit arguments about relationships among the course subjects. In the "Reverse Rhetoric and Engineering" project, for instance,

design and communication integrated to help give a better understanding of why a toy was made the way it was or how a toy was made to satisfy a customer's needs. There were also connections between design and rhetoric. The company would use a rhetorical appeal to highlight a design aspect of their product in order to appeal to customers and grab their attention.

Similarly, "the ethnography assignment combined sociological concepts with engineering."

In other cases, connections emerged as students executed successive steps of a project: "integrating other media into the paper such as the functional model, exploded view of the solid model, and the stakeholder/features chart made it easy to synthesize information from all of these sources to draw more complex, deeper conclusions about the product." Students commented most frequently about their research into specific disabilities and the payoffs they experienced when this research informed features of their designs. ("Our job was to use this information to 
improve our product. We had to keep in mind what difficulties people with motor disabilities face and use that knowledge to adapt a remote control car and controller.")

The instructors anticipated the emergence of a particular type of synthetic connections late in the course, hoping that learning outcomes from early projects would profoundly impact students' final designs. Students reporting these connections explained the value of earlier course material both in completing the project successfully and in understanding the design process:

I like seeing the connections from what we have learned earlier in the class applying to our projects now. Seeing the Stakeholder and Function Models being applied to our projects show a glimpse of how these tools can be useful for other important projects in the future...For me these can kind of serve as the foundation of our project because anything we build has to rely on what we put in our model.

We also tied in how rhetorical appeals are used in elevator pitches during our prototype presentations to Reach and how they can be used to communicate quickly and effectively between a designer and people who are buying the product.

Despite these few examples, disappointingly, several students appeared unable to connect the final project with earlier work. One student, though, used the disability studies theme to reflect on even earlier learning, thrilling us with a connection between the field of engineering and social values she has developed outside of the classroom: "seeing how disabilities was connected with the project was also a new thing for me. In high school, my academic life never mixed with my volunteering."

\section{Student Reflections: Creating Value}

The KEEN framework explicitly identifies a range of related meanings for value-_"personal, economic, and societal"3 - and student reflections on value creation often fell fairly neatly into these categories. Economic value appeared in the most straightforward ways in reflections on the "Reverse Rhetoric and Engineering" assignment, with many mentions of top-down and bottomup cost analysis. On this assignment, our study of disability sometimes produced assertions about potential sales increases by improving the corn popper's design to accommodate children with disabilities: "with a few subtle changes to the design the market opportunities for the corn popper could drastically increase."

For our students, personal value was perceived in the ethnographic observation of engineering interns. One student attributed value to the opportunity to "gain a knowledge about how an engineering community might function and what are some of the daily tasks that an electrical engineer might do...the skills I observed I will hold onto for the rest of my life." Another agreed that "we got to see how we would have to apply our knowledge in the future. Also we experienced what hardships the engineers faced and now that we know what could go awry, we have time from now on to think about how to better the situation if need be." Students also aspired to similar value for their assigned audience of high school students: reading their written ethnographies would, according to one student, "provide an in-depth look at what engineering 
culture is like, an important part of whether or not someone would like being an engineer." Another agreed: "for someone deciding their career path, information like that in the ethnography can be invaluable, and potentially life changing." One student even perceived value in her own capabilities when she stepped out of the detached observer's role and assisted interns in modeling a part:

I helped create value when I saw that [she] was stuck having a Solidworks problem for over half an hour, and I will admit that I was clueless about some of the things she was doing. But, I was looking at what she was doing at one point and saw that one of her frustrations could be fixed with a cut extrude and then fillet. She didn't hesitate to do it, and once it worked she was surprised that I actually knew what I was doing...It showed me that I was actually learning and retaining the skills being taught in class, which I am then able to transfer and use in real world situations.

Unsurprisingly, "Creating Value" appeared most real and most fulfilling to students once they were designing for clients they had met and for the needs of real children. "It was nice to see how... faces lit up because of something we made. It was satisfying to see something that I made make an impact... because things I have made for school before usually get a grade and then are thrown away." Another student concurred: "in my opinion, our entire project is creating value for the Reach community because the children are able to play a game that they would regularly not be able to play."

While students recognized having created societal value in this project, they also expressed pride in having created economic value for their clients at Reach Services-noting that commerciallyavailable adapted toys can cost several hundred dollars, while the students were able to produce products more inexpensively. Similarly, some students analyzed the "market" for toys that were lacking in the lending library. "Reach had many toys for children. However, there are very few toys for older children," producing an opportunity for "creating a toy that Reach does not have something similar to." Another observed that "many of the games that Reach has are only one person games or toys, so by making it multiplayer this adds more value to what they are receiving."

One student pointed to the spoken and written deliverables (the Rhetoric component of the course) as being where value was primarily created: "we had to condense our thoughts and present them and their meaning. When we conclude our projects, step back, and evaluate them, we consider their value ..."

Within the KEEN framework, "Creating Value" also includes the goal of persevering through failure, which also became a recurring theme in student comments: "seventy-five percent of our ideas were thrown away as failures, but we had to move on. Only through failing multiple times could the best ideas be found." Even challenges in creating computer models were considered in this light:

I never liked asking for help because I felt uncomfortable. I learned from that failure because I realized that asking for help isn't a bad thing and in fact it cuts down time making a part because I'm not staring at the screen in confusion more than actually 
making the part. I still have a hard time on SolidWorks but I least I have people around me who I can ask for help.

Of course, some students' ideas of persistence through failure were rather minimalistic and/or reductive, such as "trying to define a sketch" in SolidWorks, or having trouble printing out their projects - according to one student, "possibly the worst problem to have."

\section{Assessment of the KEEN Engineering Skillset}

Along with the " $3 \mathrm{C}$ 's" of the entrepreneurial mindset, the KEEN framework includes an inventory of engineering skills within the broad categories of defining opportunities, designing solutions, and achieving impact. For the KEEN Engineering Skillset, we were able to use a simpler method, with students rating the extent to which they had used different skills at the end of each week. Students were asked to rate the extent of their work (high, medium, low, or none) on a given skill during the week; faculty independently rated students' work using the same scale. Neither students nor faculty discussed their rankings with anyone. Table 2 shows the average results for each skill at the end of week two (mid-course) and week five (end of course) from both students and faculty perspectives. In order to analyze the data, a high ranking was assigned a 4, a medium ranking was assigned a 3, a low ranking was assigned a 2 , and none was assigned a 1.

No statistical analysis was performed on the data because of the low sample size. ( 8 students and 4 faculty) We did look to see where there was a difference in perceptions. The biggest differences in week 2 perceptions were investigate the market, analyze solutions, and develop partnerships and build a team. At the end of the course, both students and faculty were asked yet again to complete the survey based on their total effort in the class.

Table 2. Learning outcomes from the three individual source courses, maintained as stated learning outcomes for the integrated studio course.

\begin{tabular}{|l|c|c|c|c|}
\hline & \multicolumn{2}{|c|}{ Week 2 of 5 } & \multicolumn{2}{c|}{ Week 5 of 5 } \\
\hline Opportunity & Students & Faculty & Students & Faculty \\
\hline Identify an opportunity & 1.6 & 2.0 & 3.9 & 3.8 \\
\hline Investigate the Market & 1.1 & 2.0 & 2.9 & 2.8 \\
\hline Create a preliminary business model & 1.1 & 1.3 & 1.8 & 1.3 \\
\hline $\begin{array}{l}\text { Evaluate technical feasibility, customer value, } \\
\text { societal benefits, and economic viability }\end{array}$ & 1.9 & 2.5 & 4.0 & 3.3 \\
\hline Test concepts quickly via customer engagement & 1.3 & 2.0 & 3.6 & 3.3 \\
\hline Assess policy and regulatory issues & 1.3 & 2.0 & 1.9 & 2.0 \\
\hline
\end{tabular}




\begin{tabular}{|l|c|c|c|c|}
\hline & & & & \\
\hline Design & & & & \\
\hline Determine the design requirements (Metrics) & 2.5 & 2.3 & 3.9 & 3.5 \\
\hline Perform technical design & 2.6 & 2.3 & 3.9 & 4.0 \\
\hline Analyze solutions & 1.9 & 3.3 & 3.8 & 3.8 \\
\hline Develop new technologies & 1.3 & 1.8 & 3.0 & 1.8 \\
\hline Create a model or prototype & 3.1 & 3.0 & 4.0 & 4.0 \\
\hline Validate functions & 2.1 & 2.0 & 3.4 & 3.5 \\
\hline & & & & \\
\hline Impact & & & & \\
\hline $\begin{array}{l}\text { Communicate an engineering solution in } \\
\text { economic terms }\end{array}$ & 1.6 & 1.5 & 3.0 & 2.8 \\
\hline $\begin{array}{l}\text { Communicate an engineering solution in terms } \\
\text { of societal benefits }\end{array}$ & 1.9 & 2.0 & 3.6 & 3.3 \\
\hline Validate market interest & 1.3 & 2.0 & 2.6 & 3.0 \\
\hline Develop Partnerships and build a team & 2.9 & 2.0 & 4.0 & 4.0 \\
\hline Identify supply chains and distribution methods & 1.1 & 1.3 & 2.1 & 1.8 \\
\hline Protect intellectual property & 2.3 & 2.8 & 2.5 & 2.0 \\
\hline
\end{tabular}

Examination of Table 2 reveals that there was closer agreement in the rankings at the end of the course. The two skills with the largest difference were develop new technologies, and evaluate technical feasibility, customer value, societal benefits, and economic viability. These differences seem reasonable because students were often using technologies that were new to them, so they considered them as new technologies. In addition students were not given in-depth instruction on how to evaluate technical feasibility, customer value, societal benefits, and economic viability. Because they discussed these skills in their written report, they were familiar with the concepts.

There were skills that both the faculty and students agreed were not practiced frequently in this first offering: create a preliminary business model, access policy and regulatory issues, identify supply chains and distribution methods, and protect intellectual property. Given that this was a first design project for entering freshmen, it was not possible for us to give high emphasis in every element. The benefit of this assessment is that the faculty can clearly see where both faculty and students think more emphasis is needed. In addition, it is helpful to know that 
students think that they have high experience in evaluating technical feasibility, customer value, societal benefits, and economic viability. When these concepts are discussed more in-depth in future classes, faculty can emphasize that what students did in their first studio was a good start and that there are more appropriate methods.

\section{Interpreting Students' Experience of the “ $3 C$ 's" and Learning Outcomes}

When it came to the "3C's," our initial tabulation of student data created some puzzles for the instructors. For instance, we regarded the final "Design for Disability" project as a comprehensive summation of earlier experiences and assignments within the course. Why, then, did students note fewer "Connections" on this project than in the preceding one? In examining such reports, we arrived at two theories about students' experiences of the C's:

1. Experience of these dimensions may exist without students' consciousness of them. In fact, explicit, intensive attention to one of them may cause others to fade into a more peripheral awareness.

2. The 3C's may best be regarded as a sequence, in which initial curiosity leads to a process of making connections, eventually enabling the creation of value.

For our students, "Reverse Rhetoric and Engineering" emphasized the formulation of questions, asking little more than curiosity of students. When they moved from a classroom to an engineering workplace to complete an ethnographic observation, that curiosity was employed to make connections between these settings, and between students' present studies and future careers. With such a payoff, the role of curiosity in creating the inquiry was less present in students' minds. Similarly, once attention shifted to creating value for a client, that part of the entrepreneurial mindset acquired priority and conscious prominence above the others that had enabled it.

As we compared the learning of our Design Studio students to those that we had observed in more conventional sections of the component courses, we were often struck by their apparently superior achievement of the specified outcomes. For example, Introduction to Design students are always expected to "Determine the needs of a stakeholder and describe the technical, social, environmental, and economic context of the problem"- a robust and progressive learning outcome. In the integrated studio course, some students reflected on the needs of stakeholders - such as users with disabilities, beyond the depth which we normally observe in stand-alone Introduction to Design courses.

A single "magic bullet," capable of replicating such studio outcomes in other sections of the component courses, would be highly desirable. Many individual features seemed to play major roles:

- A population of students who volunteered for an experimental learning experience

- Full-time instructors in both engineering and liberal arts

- Full-time participation in the course by faculty and students, with few competing demands on time 
- A faculty-student ratio that (with visiting faculty) occasionally exceeded one-to-one

- A service-learning experience supplying a real deliverable to a real client for authentic use

- An eye toward broad competencies (without necessarily retaining every individual concept, technique, or definition from all component courses)

Some of these can be achieved in stand-alone, single-discipline courses. Others can be approximated in minor, incremental ways: for instance, faculty from other disciplines can be invited to lead individual discussions, even if they are unable to serve as full-time instructors of record. It is more difficult and resource-intensive to put all of these features in place in a consistent, mutually supportive and reinforcing way.

\section{References}

1. Gross, M.D. and E.Y. Do. 1997. "The Design Studio Approach: Learning Design in Architecture Education." Design Education Workshop, Atlanta, GA.

2. Association of American Colleges \& Universities. 2009. "VALUE Rubric Development Project." https://www.aacu.org/value/rubrics

3. Kern Entrepreneurial Engineering Network. 2017. http://engineeringunleashed.com/keen/

4. Perry, W.G. 1970. Forms of Intellectual and Ethical Development in the College Years: A Scheme. New York: Holt, Rinehart, and Winston.

5. Rapaport, W.J. 2013. "William Perry's Scheme of Intellectual and Ethical Development: A Journey along the 9 'Perry' Positions." http://www.cse.buffalo.edu/ rapaport/perrypositions.html 